\title{
Observed to expected mortality ratio as the new gold standard: All that glitters is not gold
}

\author{
Talal Al-Atassi, MD, MPH, FRCSC, and Fraser D. Rubens, MD, MSc, FACS, FRCSC
}

\author{
From the Division of Cardiac Surgery, University of Ottawa Heart Institute, Ottawa, Ontario, Canada. \\ Disclosures: Authors have nothing to disclose with regard to commercial support. \\ Received for publication July 13, 2018; accepted for publication July 16, 2018; available ahead of print Aug 14, \\ 2018. \\ Address for reprints: Fraser D. Rubens, MD, MSc, FACS, FRCSC, University of Ottawa Heart Institute, 40 Ruskin \\ St, Ottawa, Ontario K1Y 4W7, Canada (E-mail: frubens@ottawaheart.ca). \\ J Thorac Cardiovasc Surg 2019;157:883 \\ $0022-5223 / \$ 36.00$ \\ Copyright (C) 2018 by The American Association for Thoracic Surgery \\ https://doi.org/10.1016/j.jtcvs.2018.07.038
}

In this issue of the Journal, Henn and colleagues ${ }^{1}$ have presented data supporting the reporting of transcatheter aortic valve replacement (TAVR) outcomes by calculating observed to expected (O:E) 30-day mortality ratios. With this metric, they have described excellent mortality outcomes with an O:E of 0.4 , and they have proposed setting an O:E of less than 0.6 as the benchmark for all TAVR programs.

The concept of reporting O:E 30-day mortality ratios may represent a fundamental change in accountability, because it provides a novel, risk-adjusted form of 30-day mortality. This is advantageous in that it can be used in both research and real-world settings. Several concerns emerge, however, when relying solely on this measure. First, the ratio is only as good as the risk score used to calculate the expected mortality. In this case, Henn and colleagues ${ }^{1}$ used the Society of Thoracic Surgeons risk score to calculate expected risks of death at 30 days, but the latter has limitations and it tends to overestimate mortality risk. If we lack confidence in the denominator, our ratio is potentially inaccurate. Further, the Society of Thoracic Surgeons risk score was not developed for the purpose of evaluating TAVR outcomes, so it has never been validated in this setting. As an alternative, we wonder whether Henn and colleagues ${ }^{1}$ should have used the Transcatheter Valve Therapies-based TAVR risk model for hospital mortality, which has been more accurately studied in this population. Second, the Society of Thoracic Surgeons risk score does not capture such important variables as chest radiation, liver cirrhosis, or frailty, all of which may increase mortality. Failure to measure these variables further increases the

\section{Reference}

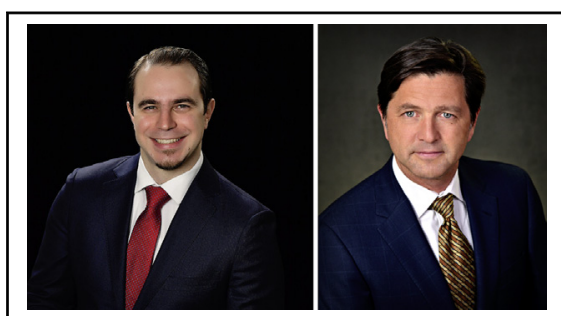

Talal Al-Atassi, MD, MPH, FRCSC (leff), and Fraser D. Rubens, MD, MSc, FACS, FRCSC (right).

\section{Central Message}

Metrics are essential to ensure quality, but now we need to achieve consensus as to which parameters we will measure to allow comparison in transcutaneous aortic valve replacement.

See Article page 874 .

difficulty of accurately comparing TAVR programs, presumably a goal of this quality program.

Another limitation to focusing on these results is their failure to capture important nonmortality TAVR medical outcomes, such as the rates of permanent pacemaker insertion or paravalvular leaks, and to capture patient-centered outcomes. One could argue that reporting O:E 30-day mortality ratio should be done in parallel with reporting these other important outcomes, which may have critical midterm and long-term implications.

In summary, the concept of reporting outcomes by using $\mathrm{O}: \mathrm{E}$ ratios is appealing. Further deliberation of the surgical and interventional community is needed, however, to decide what risk score model we should use to calculate the expected outcomes. Finally, along with 30-day mortality, we should not forget to report other important outcomes and measures of quality to portray an accurate and complete picture of any program's performance.

1. Henn MC, Zajarias A, Quader N, Sintek M, Lasala JM, Koogler K, et al. Observed to expected 30-day mortality as a benchmark for transcatheter aortic valve replacement. J Thorac Cardiovasc Surg. 2019;157:874-82. 